\title{
Formation Mechanism and Fluorescence Characterization of a Transient Assembly of Nanoparticles Generated by Femtosecond Laser Trapping
}

Wei-Yi Chiang, ${ }^{1,2, a *}$ Jim Jui-Kai Chen, ${ }^{1}$ Anwar Usman, ${ }^{3}$ Tetsuhiro Kudo, ${ }^{1}$ Kangwei Xia, ${ }^{2,4}$ Jia Su, ${ }^{2,5}$ Teruki Sugiyama, ${ }^{1,6,7}$ Johan Hofkens, ${ }^{2 *}$ Hiroshi Masuhara ${ }^{1,6 *}$

${ }^{1}$ Department of Applied Chemistry, National Chiao Tung University, 1001 Ta Hsueh Rd., Hsinchu 30010, Taiwan

${ }^{2}$ Laboratory for Photochemistry and Spectroscopy, Division for Molecular Imaging and Photonics, Department of Chemistry, Katholieke Universiteit Leuven, Celestijnenlaan 200F, 3001 Heverlee, België

${ }^{3}$ Department of Chemistry, Faculty of Science, Universiti Brunei Darussalam, Jalan Tungku Link, Gadong BE1410, Negara Brunei Darussalam

${ }^{4}$ Department of Physics, The Chinese University of Hong Kong, Shatin, New Territories, Hong Kong, China

${ }^{5}$ Department of Biology, South University of Science and Technology of China, Shenzhen 518055, China

${ }^{6}$ Center for Emergent Functional Matter Science, National Chiao Tung University, 1001 Ta Hsueh Rd., Hsinchu 30010, Taiwan

${ }^{7}$ Graduate School of Materials Science, Nara Institute of Science and Technology, 8916-5 Takayamacho, Ikoma, Nara 630-0192, Japan

a Present address: Department of Chemistry, Rice University, 6100 Main Street, Houston, Texas 77005, USA

\section{Author Information}

E-mail: weiyichiang@gmail.com (W.-Y.C.)

E-mail: johan.hofkens@kuleuven.be (J.H.)

E-mail: masuhara@masuhara.jp (H.M.) 


\section{Supplemental Information}

\section{Synthesis of asymmetrical perylene diimide dyes}

The synthesis of asymmetrical perylene diimide dyes was carried out basically following the method introduced by Tröster. ${ }^{1}$ A perylene-3,4,9,10-tetracarboxylic dianhydride ( I ) (3g) was dissolved in a potassium hydroxide aqua solution (5\% wt, $50 \mathrm{~mL}$ ) and heated at $90{ }^{\circ} \mathrm{C}$ for $4 \mathrm{hr}$ with stirring. The mixture solution was then acidulated by adding dropwisely $10 \%$ ortho-phosphoric acid until the $\mathrm{pH}$ value became 5.5-6.5. ${ }^{2}$ After further stirring it at $90^{\circ} \mathrm{C}$, the precipitate was filtered, washed and dried to obtain perylene-3,4,9,10-tetracarboxylic acid monopotassium salt (II). To synthesize monoimide (III), the monopotassium salt ( II ) was added in aqueous solution with five molar ratio of n-butylamine and its solution was stirred at room temperature for $5 \mathrm{hr}$ and further for $2 \mathrm{hr}$ at $90^{\circ} \mathrm{C}$. The reacted solution was precipitated by acidizing it with hydrochloric acid, washed by water and dried to give monoimide (III). The monoimide (III) was then reacted with 5 molar ratio of (3-aminopropyl)triethoxysilane in isoquinolin at $140^{\circ} \mathrm{C}$ for $72 \mathrm{hr}$. This reacted mixture solution was washed by hexane to remove isoquinolin and extra amine. The remaining precipitate was finally purified by chromatography with eluent composed of dichloromethane and ethanol with the volume ratio of 10/1, which yields N-butyl-N'-propyl triethoxysilane perylenediimide (IV).

${ }^{1} \mathrm{H}$ NMR (500 MHz, $\left.\mathrm{CDCl}_{3}\right) \delta 8.59(2 \mathrm{H}, \mathrm{d}), 8.58(2 \mathrm{H}, \mathrm{d}), 8.48(2 \mathrm{H}, \mathrm{s}), 8.47(2 \mathrm{H}, \mathrm{s})$, $4.19(4 \mathrm{H}, \mathrm{q}), 3.83(6 \mathrm{H}, \mathrm{q}), 1.88(2 \mathrm{H}$, quin $), 1.76(2 \mathrm{H}$, quin $), 1.48(2 \mathrm{H}, \mathrm{sex}), 1.23(9 \mathrm{H}$, t), $1.01(3 \mathrm{H}, \mathrm{t}), 0.78(2 \mathrm{H}, \mathrm{t})$.

( I )

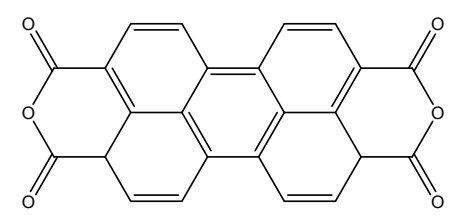

(III)

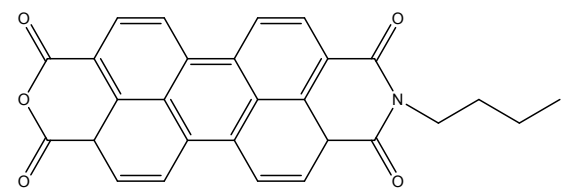

(II)

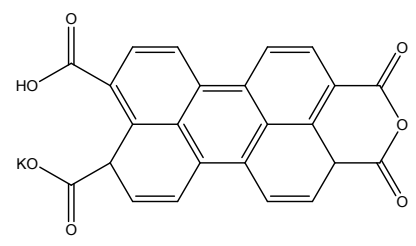

(IV)

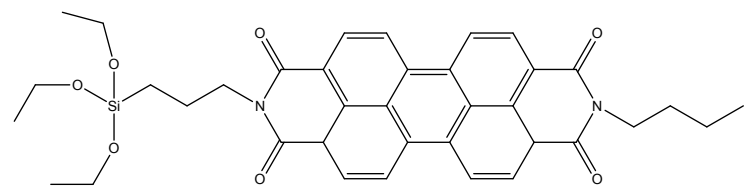

Figure S 1 ( I ) perylene-3,4,9,10-tetracarboxylic dianhydride. ( II ) perylene-3,4,9,10-tetracarboxylic acid monopotassium salt. (III) N-butyl-3,4,9,10-perylenetetracarboxylic monoanhydride monoimide. (IV) N-butyl-N'-propyl triethoxysilane perylenediimide. 


\section{Zeta potential measurement of viscosity dependence}

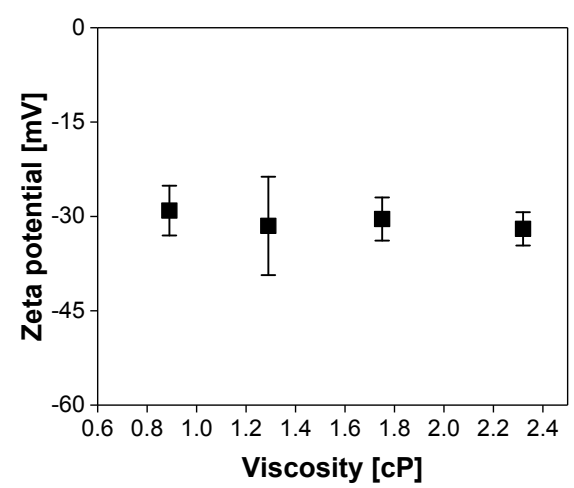

Figure S 2 The Zeta potential of silica nanoparticles was not changed by adding EG into water. This indicates that the surface condition of nanoparticles is unchanged and the nanoparticles are well distributed in solution.

\section{Preparation of PDI-silica nanoparticles}

$3 \mathrm{~g}$ of dried $100 \mathrm{~nm}$ silica nanoparticles was dispersed in $5 \mathrm{~mL}$ of $50 \mathrm{mM}$ of $\mathrm{PDI} /$ chloroform solution. The solution was sonicated for $1 \mathrm{~h}$ and stirred in room temperature for $12 \mathrm{~h}$ to synthesize PDI-silica nanoparticles. PDI-silica nanoparticles were washed with chloroform for 3 times to remove unreactive PDI molecules and finally dispersed in pure water. The nanoparticle density is controlled to be $3.8 \times 10^{2}$ nanoparticles $/ \mu \mathrm{m}^{3}$.

The preparation of Low-PDI and High-PDI were similar to above one. Low-PDI was 3 $\mathrm{g}$ of dried $500 \mathrm{~nm}$ silica nanoparticles dispersed in $5 \mathrm{~mL}$ of $10 \mathrm{mM}$ of PDI/chloroform solution. High-PDI was $3 \mathrm{~g}$ of dried $500 \mathrm{~nm}$ silica nanoparticles dispersed in $5 \mathrm{~mL}$ of $500 \mathrm{mM}$ of PDI/chloroform solution. Both of the solutions were sonicated for $1 \mathrm{~h}$ and stirred in room temperature for $12 \mathrm{~h}$ to synthesize PDI-silica nanoparticles. PDI-silica nanoparticles were washed with chloroform for 3 times to remove unreactive PDI molecules and finally dispersed in pure water.

\section{References}

(1) Tröster, H. Untersuchungen Zur Protonierung von Perylen-3,4,9,10Tetracarbonsiiurealkalisalzen. Dye. Pigment. 1983, 4, 171-177.

(2) Nagao, Y.; Naito, T.; Abe, Y.; Misono, T. Synthesis and Properties of Long and Branched Alkyl Chain Substituted Perylenetetracarboxylic Monoanhydride Monoimides. Dye. Pigment. 1996, 32, 71-83. 